\title{
Life history and adult dynamics of Bactrocera dorsalis in the citrus orchard of Nanchang, a subtropical area from China: implications for a control timeline
}

\author{
Xiaozhen $\mathrm{Li}^{\mathrm{a}, *}$, Haiyan Yang ${ }^{\mathrm{b}}$, Tao Wang ${ }^{\mathrm{a}}$, Jianguo Wang ${ }^{\mathrm{a}}$, Hongyi Wei ${ }^{\mathrm{a}}$ \\ a College of Agronomy, Jiangxi Agricultural University, Nanchang 330045 China \\ b Industrial Development Office, Jiangxi Agricultural University, Nanchang 330045 China \\ *Corresponding author, e-mail: 1xziiz@163.com
}

Received 20 Jun 2018

Accepted 20 Jun 2019

\begin{abstract}
Bactrocera dorsalis (Hendel) has invaded Jiangxi, a subtropical area of China and poses a serious threat to its host crops, especially citrus fruits. Thus far, the ecological characteristics of $B$. dorsalis in this area remain unclear, which has restricted prevention and control efforts. A study was carried out in citrus orchards in Nanchang, a region of north Jiangxi, between 2008 and 2014 to clarify the life history and adult dynamics of B. dorsalis, and then a management plan for $B$. dorsalis were recommended. The results showed that $B$. dorsalis exhibits mixed voltinism, between 4 and 5 generations per year, and overwinters at the fourth and fifth generation pupae stage. Adult stages are active from early May to mid-January of the following year with a distinct peak density between October and November. To control this pest, we suggested that trapping adults using methyl eugenol (ME) and hydrolyzed protein (HP) as lures and removing damaged citrus fruits should be carried out from early May to early December and from late August to mid-December, respectively. Turning soil to eliminate overwintering pupae should begin in late December and end in late February of the following year, and fruit bagging should be performed from mid-August to late October. Releasing parasitic wasps or chemical pesticides would be most effective from mid-August to early September. These results will be useful for citrus farmers and orchard managers as they provide a clear control timetable for applying various control measures, which can help prevent or limit the occurrence of $B$. dorsalis and its damage to citrus orchards.
\end{abstract}

KEYWORDS: Bactrocera dorsalis, life cycle, population dynamics, citrus orchards, control timeline

\section{INTRODUCTION}

Citrus are among the most widely cultivated types of fruit trees in the world. Global production is close to 123 million tons per annum ${ }^{1}$. In China, citrus cultivation occurs in over 19 provinces, especially in regions south of the Yangtze River. Among these, Jiangxi province is a major citrus-producing region, with approximately 322000 hectares of plantations, which, in 2014, produced 3450000 tons of citrus $^{2}$. Both Gannan navel orange (Citrus sinensis (L.) Osbeck) and Nanfeng honey orange (C. reticulata Blanco cv. Kinokuni) are the dominant varieties in this area. At the end of twentieth century, Bactrocera dorsalis (Hendel) invaded the Jiangxi region ${ }^{3}$ (Fig. 1) and posed a serious threat to local citrus production.

This pest is a highly invasive species of tephritid fruit fly that is endemic to Asia, but has been introduced to Hawaii, the Mariana Islands and subSaharan countries over the last century ${ }^{4,5}$. After introduction, B. dorsalis can easily disperse and severely damage as it has a high reproductive potential (between 400-1800 eggs per female), a short life cycle (more than 5 generations per year in most tropical regions), a rapid dispersal ability (diffusion range $50-100 \mathrm{~km}$ per year) and a broad host range (46 plant families and more than 250 types of fruits and vegetables) ${ }^{6,7}$. Males of the species respond strongly to methyl eugenol (ME) and this is used for monitoring and estimating populations ${ }^{8,9}$. Female adults lay eggs in clutches under the skin of fruits by piercing the tissue with their ovipositor. When the eggs hatch, the larvae feed on the flesh, causing fruits to rot and drop ${ }^{10}$. These damaged fruits include honey orange (C. reticulata Blanco cv. Kinokuni), navel orange [C. sinensis (L.) Osbech cv. Newhall, C. sinensis (L.) Osbech cv. Skaggs Bonanza, C. sinensis (L.) Osbeck cv. Washington], pomelo [Citrus maxima (Burm.) Merr.], mango (Mangifera indica L.), guava (Psidium guajava L.), papaya (Carica papaya L.), and carambola (Aver- 


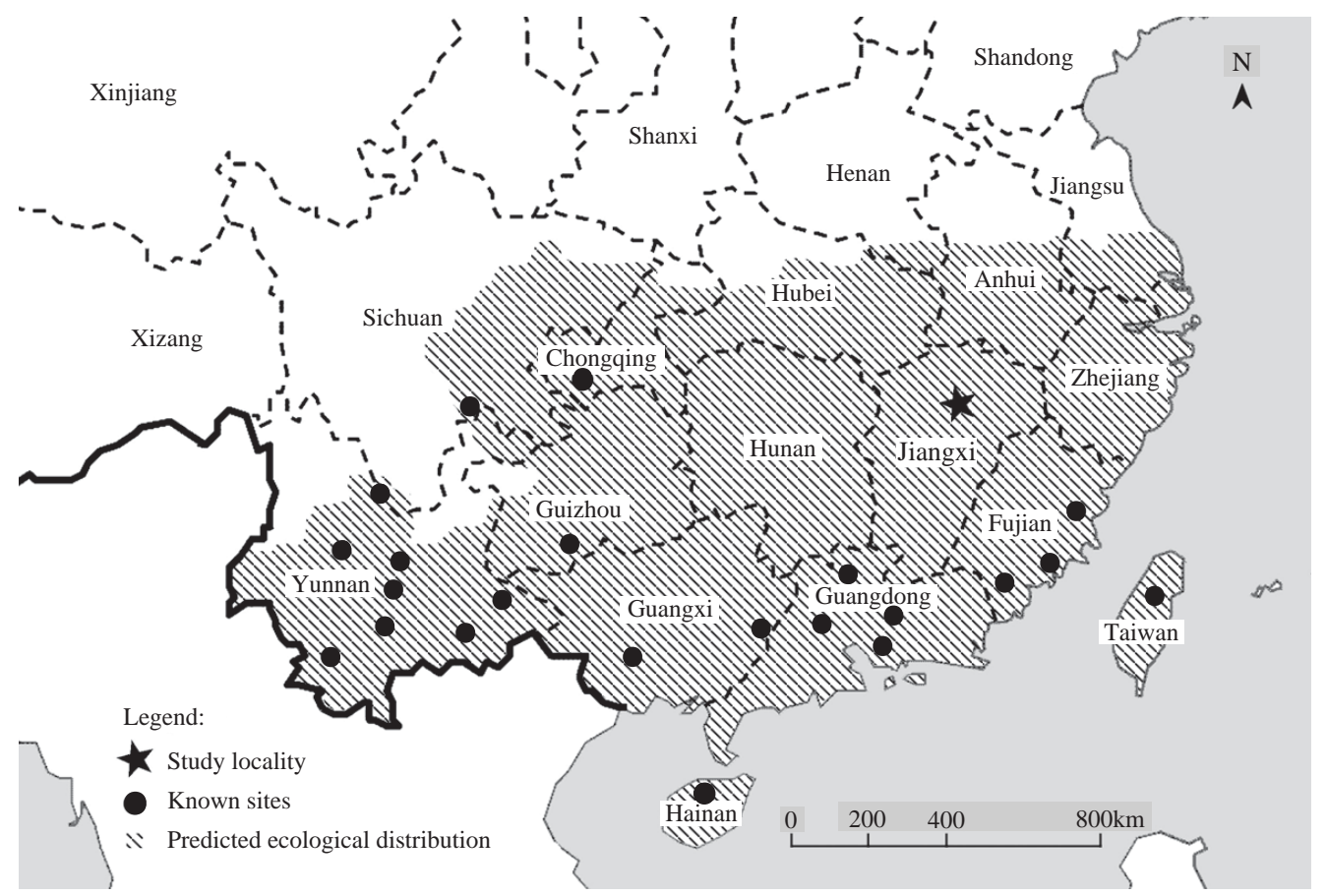

Fig. 1 Study locality and ecological distribution of $B$. dorsalis in China.

rhoa carambola L.) ${ }^{11}$. In China, damage to fruits from $B$. dorsalis has caused serious economic losses for many years. For example, the citrus losses in Wuxi, Jiangsu province were estimated to range from $20-30 \%$ of the total crop in $2005^{12}$, and a similar loss in Suzhou and Shanghai occurred in $2006^{13}$. In Fuzhou, Fujian province, B. dorsalis significantly impacted star fruit, and the highest catches in carambola orchards exceeded 900 adults per trap per week in 2008 and $2009^{14}$. Thus $B$. dorsalis is a destructive pest in areas where it occurs $^{15}$.

Several control and monitoring measures have been employed in recent years to limit damage from $B$. dorsalis. These include (1) monitoring populations using traps with methyl eugenol (ME) or hydrolyzed protein (HP) in the Goa region, India and Peshawar, Pakistan ${ }^{16}$, (2) removing or destroying infested fruits in a timely manner, and (3) eliminating or reducing pupae by turning soil in Yunnan, China ${ }^{17}$, (4) bagging fruit to prevent female oviposition on fruit skins in Fujian, China, (5) releasing parasitic wasps for Spalangia endius Walker and Pachycrepoideus vindemmiae (Rondani) in Hawaii and French Polynesia ${ }^{18}$, and (6) cover sprays using pesticides or baits in Rota, Mariana Islands and Hawaii ${ }^{19}$. Nonetheless, except for chemical control, these control measures have rarely been used in many fruit and vegetable bases where it outbroke in China. This is partly attributable to a traditional dependence on pesticides. In addition, the timing of when and how to perform other effective control measures is still unknown for most areas or habitats/crops. To improve the acceptance and use of non-chemical controls by farmers, it is necessary to further refine these control measures using guidelines based on the biology and ecology of $B$. dorsalis populations.

However, information on the occurrence parameters of $B$. dorsalis remains poorly understood in the Nanchang area. The objective of this study was initially to clarify its life history and population dynamics in this area, using common approaches that involved the rearing from 2009-2012 and trapping from 2008-2014. Then, an optimal control timeline on the five available control measures based on this information was developed to be used by farmers to prevent the occurrence, development and damage of this destructive fruit pest in citrus orchards of this area and even those with similar habitats or environmental conditions.

\section{MATERIALS AND METHODS}

\section{Study site}

The study site was located at the Jiangxi Agriculture University Experiment Farm of Northwest 

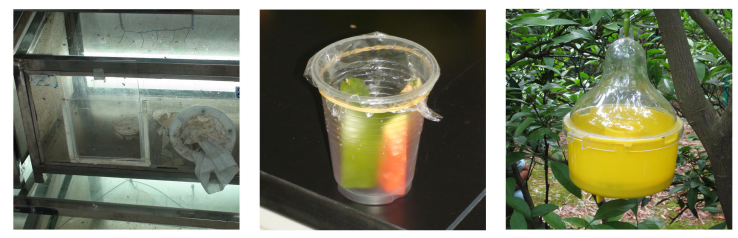

Fig. 2 Population rearing and adult trapping. Left, rearing box; Middle, egging cup; Right, trapping adult in citrus orchard.

Nanchang, Jiangxi $\left(115^{\circ} 49^{\prime}\right.$ E, $\left.28^{\circ} 46^{\prime} \mathrm{N}\right)$ (Fig. 1). The farm contains approximately 15 hectares of citrus (C. reticulata, C. sinensis) along with kumquat (Fortunella margarita Lour.), peach [Prunus persica (L.) Batsch], pear [Pyrus pyrifolia (Burm. f.) Nakai], grape (Vitis vinifera L.), and red bayberry [Myrica rubra (Lour.) Set Zucc.]. These crops and their planting areas did not change between 2008 and 2014. But due to the severe damage of $B$. dorsalis on citrus, since 2010 farmers removed infested fruits and used cover sprays (beta-cypermethrin and malathion) during periods of citrus fruit growth and ripening. The area has four distinct seasons, with a longer summer and winter and a shorter spring and autumn. The annual average temperature is approximately $17^{\circ} \mathrm{C}$ with summer maxima of $40^{\circ} \mathrm{C}$ and winter minima of $-10^{\circ} \mathrm{C}$. The seasonal differences cause large fluctuations in the occurrence and abundance of the pest and the damage it causes.

\section{Life history}

B. dorsalis population was initially collected from the farm, from 50-60 infested citrus fruits (C. sinensis), during October, 2009. The infested fruits were randomly placed in 6 plastic trays each with approximately $5 \mathrm{~cm}$ of soil as a pupation medium for mature larvae exiting the fruits. A total of about 280 overwintering pupae in the soil in the tray were obtained, which were used in experiments.

These overwintering pupae from infested fruits were kept together in a tray, and placed in a rearing cage. About 220 adults emerged from these pupae the next year. Perforated (approximately 1 $\mathrm{mm}$ holes) transparent plastic cups containing sliced mature citrus fruit and then covered with plastic film were used as egging cups (Fig. 2). Once every 2 days during the laying period, an egging cup every time was placed in the rearing cage for 24 hours, and eggs propagated from these adults were laid on the inner wall of egging cups. In order to clarify the generation of $B$. dorsalis, these eggs from the first
Table 1 Trapping period of $B$. dorsalis over a seven-year period at the Jiangxi Agriculture University Experiment Farm, Northwest Nanchang, Jiangxi.

\begin{tabular}{lcc}
\hline Trapping period & \multicolumn{2}{c}{ Number of trap } \\
\cline { 2 - 3 } & Steiner & McPhail \\
\hline 28 April-17 December 2008 & 3 & 2 \\
1 May-18 December 2009 & 3 & 2 \\
8 May 2010-2 January 2011 & 3 & 2 \\
28 April-18 December 2011 & 3 & 2 \\
29 April-31 December 2012 & 4 & 3 \\
30 April-28 December 2013 & 3 & 2 \\
23 April-16 December 2014 & 3 & 2 \\
\hline
\end{tabular}

and last period of adults (no count) were transferred to artificial larval diets with a little water to establish separate population. The same procedure was adopted for rearing each generation of $B$. dorsalis between 2010 and 2011. Adults were supplied with fresh citrus fruits, beer yeast, honey and water as food, and larvae were raised on artificial diets that included white sugar, beer yeast, water, wheat bran, methyl-p-hydroxybenzoate and potassium sorbate ${ }^{20}$. During the rearing, we recorded the developmental stage and generation number in relation to the life cycle of this fruit fly.

All these processes were carried out in an insect rearing room with two windows $(270 \mathrm{~cm} \times 180 \mathrm{~cm})$, about $300 \mathrm{~m}$ from the experiment farm. In order to simulate the four seasons as much as possible, the windows were always open for ventilation and daylighting, and heating, humidification and lighting equipments were not used, except for an exception with artificial light during our observations so as to observe more clearly. So, its life history observed could be a good reflection of what was happening outdoors.

\section{Adult dynamics}

The adult dynamics of $B$. dorsalis were determined by trapping with ME-baited (3 ml) Steiner traps and HP-baited (0.5 1, $24 \mathrm{~g} / \mathrm{l})$ McPhail traps in the experimental orchard from 2008-2014 (Fig. 2). In the trapping, we kept the same concentration and dose of the two lures when renewed each time. The trapping started in late April or early May (2009 and 2010) as B. dorsalis adults usually begin to occur in early May in Nanchang area ${ }^{22}$ and ended in midlate December or early January the next year (2011) when no adults were captured (Table 1 ).

A total of 3-4 Steiner and 2-3 McPhal traps were deployed each year for the duration of the 
study (Table 1). The traps in section A and B were suspended from tree branches, hedges or metal poles approximately $1.0-1.5 \mathrm{~m}$ above the ground in locations not completely covered by foliage or in direct sunlight and $40-50 \mathrm{~m}$ apart to avoid interference. ME was changed monthly and HP semimonthly ${ }^{10}$. The traps were usually checked weekly, but sometimes advanced or delayed for 1-2 days due to weather or human factors. We replaced in time some traps missed or impaired. Captured adults of $B$. dorsalis and other tephritid species were identified and counted according to the characteristics described by Drew and Raghu ${ }^{4}$.

\section{Control timeline}

Through the study for $B$. dorsalis in Nanchang, Jiangxi, we obtained information that included the overwintering stages of $B$. dorsalis, the number of generations per year, the duration of each generation and developmental stage, and the season and peak period of adult occurrences. Then, we, according to the information, formulated a specific control timeline for $B$. dorsalis on each control measure above-mentioned.

\section{Statistical analysis}

All the data were analyzed using SPSS 13.0. Relative trapping efficiency of the traps was compared using Wilcoxon signed ranks test for two related samples in nonparametric tests. Means and standard error of the mean (SEM) of adults collected using ME or HP lures each week were calculated using Explore procedures. Generalized linear models were developed, which accounted for the changing adult captures over the trapping period from 20082014.

\section{RESULTS}

\section{Life history}

In 2010 and 2011, number of $B$. dorsalis generations was similar, but the occurring time of different developmental stages in each generation was slightly different. For example, adults started occurring on May 1 in 2010 and the last adults died on December 21. In 2011, adults occurred on April 21 and died on January 10 the following year. But in both years, the first generation eggs and larvae appeared in late May. According to the developmental process of each stage in the two years, we incorporated the life history of $B$. dorsalis in the Nanchang area, Jiangxi.

Table 2 showed that $B$. dorsalis exhibits mixed voltinism of between 4 and 5 generations per year.
The fourth and fifth generation pupae overwinter in loose soil. Overwintering pupae emerge as adults beginning in late April each year. First generation eggs begin to occur in late May and end in early July, while second, third, fourth, and fifth generation eggs appear in early July, mid-August, late September, and early November, respectively. Correspondingly, the timing of larvae lagged behind that of eggs for 2-4 days (the duration of eggs) in each generation. There is some generation overlap, due to the longevity of adults and the long oviposition period (the average longevity is 84.8 days; and the oviposition period is more than 30 days). We did not observe eggs from fifth generation adults in any one year.

\section{Seasonal dynamics}

A total of 28843 fruit flies were captured through the 37 traps. In addition to B. dorsalis (24764), fruit fly species included B. (Zeugodacus) tau (Walker) (2707), B. (Z.) scutellata (Hendel) (1267), B. (Z.) cucurbitae (Coquillett) (100), Dacus (Callantra) trimacula (Wang) (5), and other non-tephritid dipterous insects (no count). As for $B$. dorsalis, trapping efficiency using $\mathrm{ME}$ as a lure was significantly better than trapping using HP as a lure in every year, based on a Wilcoxon signed rank test (Table 3).

From 2008-2014, the $B$. dorsalis adult captures with both types of lures exhibited large fluctuations at different dates. Generally, adults were first captured in early May, and kept low density levels till mid-August. Subsequently, they would gradually increase to a clear density peak between early September and late November. After December, adult catches were drastically reduced as the temperature decreased. The peak values of $B$. dorsalis adults also varied widely across the study years. The maximum peak value was 387 adults per trap per week (ME) and 56.5 adults per trap per week (HP) on November 14, 2010, while the minimum was 80.33 adults per trap per week (ME) on November 6 , 2014, and 4.33 adults per trap per week (HP) on September 10, 2012. Comparatively, adult captures per trap per week were particularly high in 2010 and low in 2012 and 2014 at the experimental site (Fig. 3).

\section{Annual fluctuation}

In order to understand the year-to-year fluctuation, we calculated the average captures with $\mathrm{ME}$ and $\mathrm{HP}$ as lures in these years. The results showed that the average number was $42.10,47.30,54.75$, 
Table 2 Life history of $B$. dorsalis in Nanchang, Jiangxi.

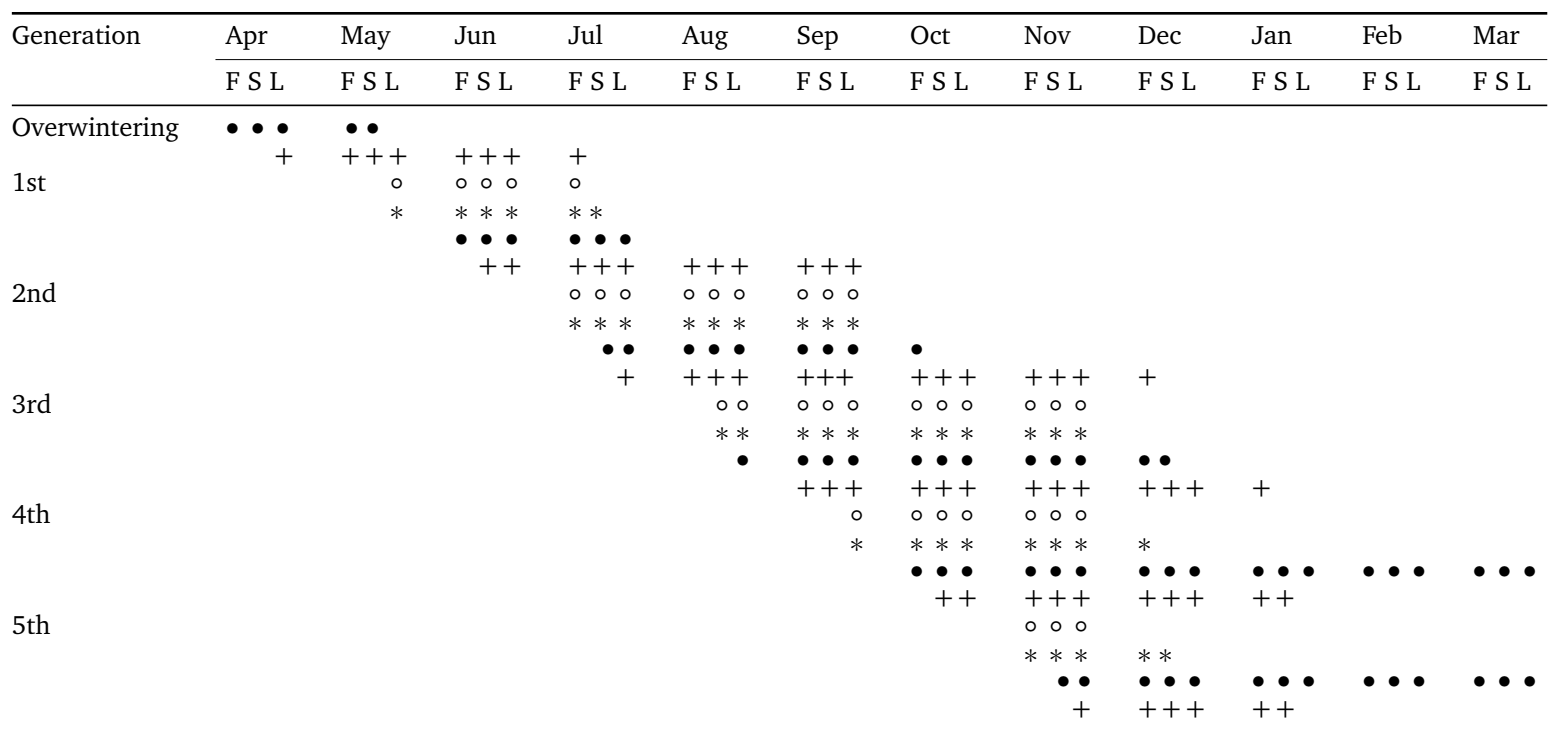

+ adult; o egg; * larva; • pupa. F, S, and L represent the first, second, and last 10-day period of a month, respectively.

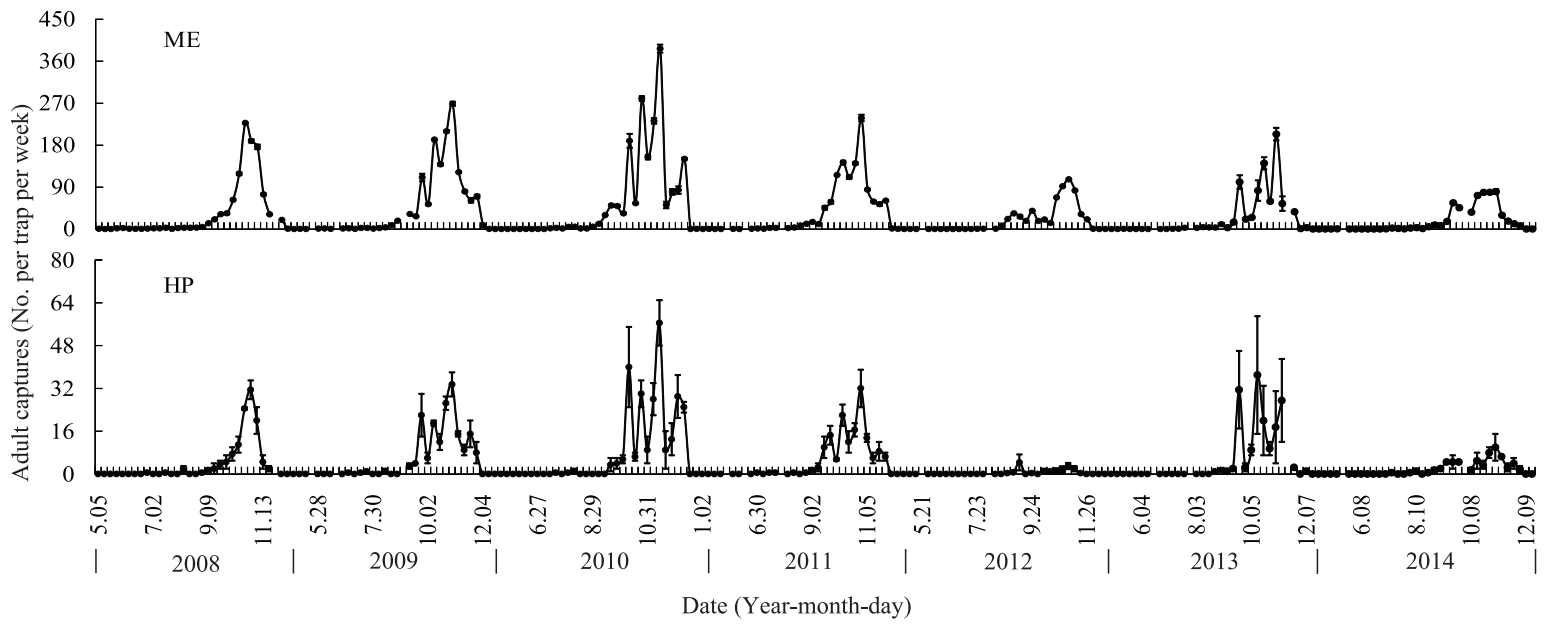

Fig. 3 Average catches (mean \pm SEM) of $B$. dorsalis adults with ME and HP as lures on specific dates between 2008 and 2014 in Nanchang, Jiangxi.

39.04, 18.22, 25.01, and 17.54 adults per trap per week (ME), and was 3.44, 5.60, 7.28, 4.92, 0.49, 4.97, and 1.85 adults per trap per week (HP) from 2008-2014, respectively. Generalized linear models indicated that the average captures with the two lures slightly declined across these study years. The two linear equations were $y=8701.56-4.31 x$ $\left(R^{2}=0.62, p<0.01\right)$ for ME and $y=1024.24-$ $0.51 x\left(R^{2}=0.51, p<0.05\right)$ for HP (Fig. 4).

\section{Suggestions for optimal control scheduling}

Based on the life history and population dynamics of $B$. dorsalis established in this study, the citrus growth stage in this region, we incorporated the six available measures for $B$. dorsalis control into a management plan. Table 4 suggests that efforts to trap adults with ME or HP (control measure A) and to remove injured fruits in a timely manner (control measure B) should be conducted from early May to early December and from late August to midDecember, respectively. Turning soil to eliminate pupae (control measure C) should begin in late December and end in late February. Fruit bagging to prevent oviposition (control measure D) should be performed from mid-August to late October. The most effective period for releasing parasitic wasps 


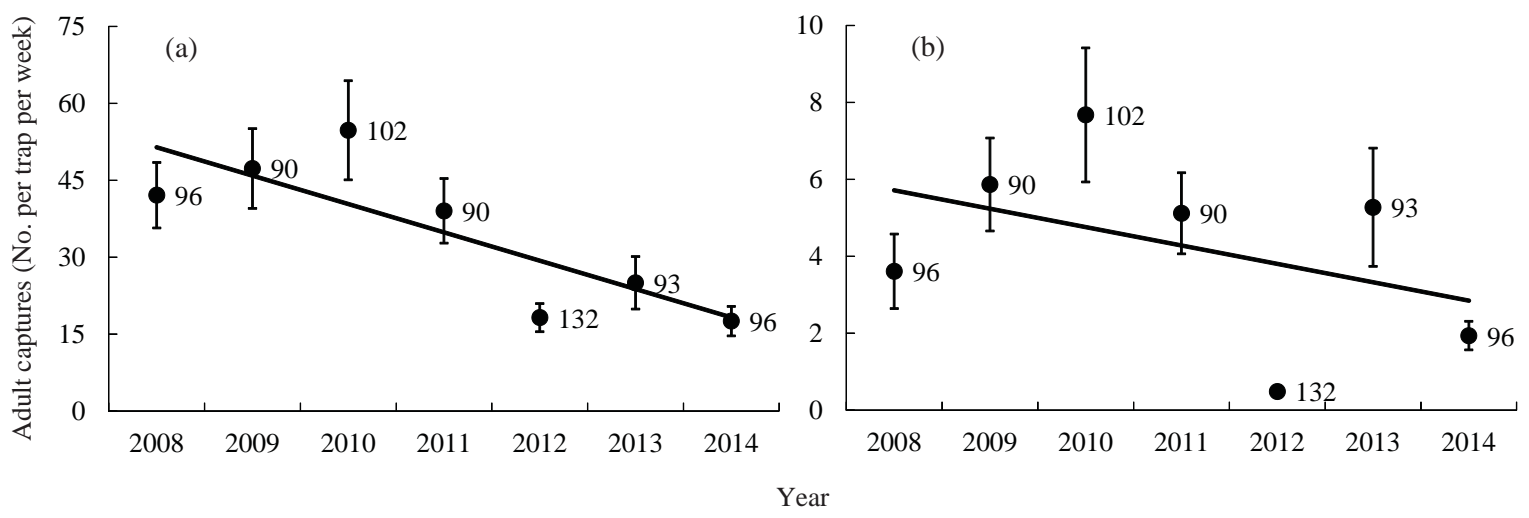

Fig. 4 Annual fluctuations of $B$. dorsalis adult captures in Nanchang, Jiangxi from 2008-2014. (a) Relation between the average captures of $B$. dorsalis adult using ME as a lure $(\bullet)$ and years of trapping. Linear model of catches (black line), $y=8701.56-4.31 x, F=12.60, d f=1676, p<0.001, R^{2}=0.62$. (b) Relation between the mean catch of $B$. dorsalis adult using HP as a lure $(\bullet)$ and years of trapping. Linear model of catches (black line), $y=1024.24-0.51 x, F=5.42$, $d f=1460, p=0.020, R^{2}=0.51$. Data are mean \pm SEM. Values beside the black spots $(\bullet)$ are the sampling numbers for each year.

Table 3 Comparison on the trapping efficiency between ME and HP from 2008-2014 (adults/trap/week) based on nonparametric tests.

\begin{tabular}{|c|c|c|c|c|c|}
\hline Year & Species & $\begin{array}{c}\mathrm{ME} \\
\text { mean } \pm \mathrm{SE}\end{array}$ & $\begin{array}{c}\mathrm{HP} \\
\text { mean } \pm \mathrm{SE}\end{array}$ & Z & $\begin{array}{r}\text { test } \\
p\end{array}$ \\
\hline 08 & $\begin{array}{l}\text { B. dorsalis } \\
\text { B. tau } \\
\text { B. scutellata } \\
\text { B. cucunbitae }\end{array}$ & $\begin{array}{r}32.10 \pm 6.39 \\
2.16 \pm 0.30 \\
0.45 \pm 0.04 \\
0.10 \pm 0.04\end{array}$ & $\begin{array}{l}3.61 \pm 0.97 \\
3.29 \pm 0.66 \\
1.75 \pm 0.48 \\
0.16 \pm 0.06\end{array}$ & $\begin{array}{l}-4.71 \\
-1.77 \\
-3.74 \\
-0.58\end{array}$ & $\begin{array}{r}<0.001 \\
0.077 \\
<0.001 \\
0.564\end{array}$ \\
\hline 09 & $\begin{array}{l}\text { B. dorsalis } \\
\text { B. tau } \\
\text { B. scutellata } \\
\text { B. cucunbitae }\end{array}$ & $\begin{array}{r}47.30 \pm 7.79 \\
1.97 \pm 0.29 \\
0.49 \pm 0.11 \\
0.07 \pm 0.03\end{array}$ & & $\begin{array}{l}-4.63 \\
-2.35 \\
-3.62 \\
-1.47\end{array}$ & $\begin{array}{r}<0.001 \\
0.019 \\
<0.001 \\
0.142\end{array}$ \\
\hline 10 & $\begin{array}{l}\text { B. dorsalis } \\
\text { B. tau } \\
\text { B. scutellata } \\
\text { B. cucunbitae }\end{array}$ & $\begin{array}{r}54.75 \pm 9.65 \\
2.32 \pm 0.36 \\
0.60 \pm 0.14 \\
0.10 \pm 0.04\end{array}$ & $\begin{array}{l}7.68 \pm 1.74 \\
3.78 \pm 0.73 \\
2.43 \pm 0.62 \\
0.13 \pm 0.06\end{array}$ & $\begin{array}{l}-4.29 \\
-2.23 \\
-3.84 \\
-0.58\end{array}$ & $\begin{array}{r}<0.001 \\
0.026 \\
<0.001 \\
0.564\end{array}$ \\
\hline 11 & $\begin{array}{l}\text { B. dorsalis } \\
\text { B. tau } \\
\text { B. scutellata } \\
\text { B. cucunbitae }\end{array}$ & $\begin{array}{r}39.04 \pm 6.29 \\
1.61 \pm 0.26 \\
0.46 \pm 0.11 \\
0.04 \pm 0.03\end{array}$ & $\begin{array}{l}5.12 \pm 1.05 \\
2.63 \pm 0.41 \\
2.02 \pm 0.51 \\
0.07 \pm 0.04\end{array}$ & $\begin{array}{l}-4.46 \\
-3.94 \\
-3.67 \\
-0.26\end{array}$ & $\begin{array}{r}<0.001 \\
<0.001 \\
<0.001 \\
0.792\end{array}$ \\
\hline 12 & $\begin{array}{l}\text { B. dorsalis } \\
\text { B. tau } \\
\text { B. scutellata } \\
\text { B. cucunbitae }\end{array}$ & $\begin{array}{r}18.21 \\
1.64 \\
0.33 \\
0.05\end{array}$ & & $\begin{array}{l}-3.92 \\
-1.93 \\
-4.46 \\
-0.25\end{array}$ & $\begin{array}{r}<0.001 \\
0.053 \\
<0.001 \\
0.803\end{array}$ \\
\hline$\overline{13}$ & $\begin{array}{l}\text { B. dorsalis } \\
\text { B. tau } \\
\text { B. scutellata } \\
\text { B. cucunbitae }\end{array}$ & $\begin{array}{r}25.01 \pm 5.11 \\
1.54 \pm 0.21 \\
0.49 \pm 0.11 \\
0.04 \pm 0.03\end{array}$ & $\begin{array}{l}5.27 \pm 1.53 \\
3.19 \pm 0.58 \\
2.42 \pm 0.55 \\
0.14 \pm 0.06\end{array}$ & $\begin{array}{l}-4.11 \\
-2.66 \\
-3.38 \\
-1.47\end{array}$ & $\begin{array}{r}<0.001 \\
0.008 \\
0.001 \\
0.140\end{array}$ \\
\hline 14 & $\begin{array}{l}\text { B. dorsalis } \\
\text { B. tau } \\
\text { B. scutellata } \\
\text { B. cucunbitae }\end{array}$ & $\begin{array}{r}17.54 \pm 2.87 \\
1.55 \pm 0.24 \\
0.36 \pm 0.10 \\
0.05 \pm 0.02\end{array}$ & $\begin{array}{l}1.93 \pm 0.37 \\
3.02 \pm 0.58 \\
2.12 \pm 0.54 \\
0.11 \pm 0.05\end{array}$ & $\begin{array}{l}-4.29 \\
-2.96 \\
-3.79 \\
-0.83\end{array}$ & $\begin{array}{r}<0.001 \\
0.003 \\
<0.001 \\
0.405\end{array}$ \\
\hline
\end{tabular}

(control measure E) or applying chemical pesticides (control measure F) ranges from mid-August to early and mid-September. Overall, coordinating the periods of citrus fruit enlargement and fill with selection and implementation of the control measures can be crucial in reducing populations and limiting the damage of $B$. dorsalis in citrus orchards.

\section{DISCUSSION}

B. dorsalis was first recorded in Taiwan in $1912^{22}$ but has now spread to most of the countries in the Asia-Pacific region including India, Pakistan and Thailand $^{23-25}$. Due to its wide distribution and ability to cause serious damage to various crops, $B$. dorsalis is considered to be a major pest that urgently requires efficient management tactics ${ }^{26}$. Many types of control measures have been developed to ensure the safe production of $B$. dorsalis host crops. However, these have had little success in minimising damage, largely due to the lack of information about when to implement the control measures in specific areas or for specific crops. To improve control, we proposed a control timeline for $B$. dorsalis in conjunction with the growth stages of citrus for Nanchang, Jiangxi. This work not only provides some basic information about $B$. dorsalis outbreaks and damage but also provides a control timetable usable directly by farmers for reducing or eliminating this fruit fly in the specific habitat of citrus orchards.

Before incorporating the control timeline, our rearing and trapping for $B$. dorsalis suggested its occurrence pattern in the Nanchang area of China; a population can complete 4-5 generations per year, and overwinter in loose soil as pupae. Adults begin 
Table 4 Effective control periods for B. dorsalis using five types of control measures by citrus growth stage and season:

\begin{tabular}{|c|c|c|c|c|c|c|c|c|c|c|c|c|}
\hline Control & Jan & Feb & Mar & Apr & May & Jun & Jul & Aug & Sep & Oct & Nov & Dec \\
\hline
\end{tabular}

Control A

Control B

Control C

Control D

Control E

Control F

\footnotetext{
$\dagger$ Control measures: A, adult trapping with ME or HP as lures; B, removing damaged fruit in a timely manner; C, turning soil to eliminate pupae; D, fruit bagging to prevent oviposition on fruit skins; E, releasing parasitic wasps; F, applying chemical pesticides. F, S, and L represent the first, second, and last 10-day periods in a month, respectively.

$*$ Disclaimer: The information contained herein is accurate to the best of the authors' knowledge and beliefs. The recommendations and results stated here, unless otherwise acknowledged, are based upon the life history and adult dynamics of $B$. dorsalis in Nanchang, China.
}

to occur in early May, present at low levels during May-August, peak from September-November and decline since December. It showed that the peak of $B$. dorsalis adults in this region matches perfectly the availability of ripe fruits from Citrus spp. By comparing these rules in the other regions with ours, it is apparent that these are similar with Hubei and Shanghai ${ }^{27}$, but different from Guangdong, Fujian and Yunnan where B. dorsalis overwinters as adults ${ }^{28}$, and the first-generation eggs begin to occur in $\mathrm{March}^{29}$. The peak period for B. dorsalis adults in Nanchang, Jiangxi is also different from Fujian, where the peak generally occurred between August and September ${ }^{30}$, from Guangdong, which has two density peaks, one in June and July and the other in September and October ${ }^{31}$, and from Yunnan, where the peak occurred in June ${ }^{32}$. These differences were caused by the different climate conditions and natural habitats, especially winter temperature and available hosts ${ }^{33,34}$.

Similarly, there were some changes in the dynamics of $B$. dorsalis adults during 2008-2014 as well. For example, when compared to 2010, the average captures and maximum peak values were lower in 2012 and 2014. But overall, the B. dorsalis population decreased across the study years, in particular since 2010, at the experiment site. This, besides the influence from seasonal differences between years, was likely owing to some control measures (such as adult trapping since 2008, the removal of damaged fruits and the use of chemical pesticides since 2010) taken by us and farmers.

We, by citrus growth stage and season, incorporated the specific control timeline on six types of control measures according to the occurrence rules of $B$. dorsalis in the Nanchang area. When using the control timeline, the following points need special attention. First, the trapping should be especially concentrated from late August to midNovember due to the high density of $B$. dorsalis adults during this period. Second, the key timing of turning soil to eliminate pupae should be focused on those days with low environmental temperature. Third, the time phase of fruit bagging should be shortened as much as possible to avoid its effect on the fruit colouring. Finally, chemical pesticides should be forbidden after fruit fill to avoid their residue and effect on citrus. In addition, the control timeline may need some adjustments among years to fit the change of $B$. dorsalis population occurrence dynamics under natural conditions.

However, we have to point out that the indoor rearing condition on $B$. dorsalis, in any case, did not completely synchronize with the real life situation outdoors. For example, it did not receive direct sunlight and rains as outdoors, adults were confined to rearing cages, and diets were provided artificially, etc. So the life history we observed might have some slight differences with that in outdoors. One of such differences was that adults began to emerge in late April in indoor conditions, but they, in the citrus orchard, were first captured in early May, which lagged behind the emerging time for about 10 days. This may be due to either adults from overwintering pupae emerged later under outdoors condition or newly emerging adults did not respond to ME (methyl eugenol) and HP (hydolyzed protein). Actually, the method to solve this problem was to rear $B$. dorsalis directly in outdoors. However, it was not easy to complete the 
study, especially in winter due to the low survival rate of pupae (below 10\% in Wuhan, Hubei which have the similar low temperature with Nanchang, Jiangxi) ${ }^{26}$. This might explain why there was a low density of $B$. dorsalis adults from May to midAugust the following year. Additionally, the control timetable we have developed is relevant for the Nanchang area and may also be applicable in areas where $B$. dorsalis encounters similar habitats or environmental conditions, including citrus orchards in Shanghai, Zhejiang, Hunan, Hubei, Sichuan, and Chongqing, China. As for the other regions, they need to be rescheduled according to the occurrence rule of $B$. dorsalis in local.

Currently, $B$. dorsalis is still spreading around the world ${ }^{16,25}$. This, except linked with the biology and ecology of $B$. dorsalis and the change of global climates and circumstances ${ }^{35,36}$, was also related to people's control measures, especially the control timeline of them. However, here we did not differentiate which of these control measures, or all them used in combination, were more efficient and economical. It is possible that $B$. dorsalis would expand further or cause outbreaks at our experimental location or in citrus orchards when no suitable control measures were adopted. But, through this study, we believe that the implementation of these control measures according to a suitable control timeline were to some extent efficient in reducing the occurrence, development and damage of $B$. dorsalis in most fruit and vegetable bases, either singly or combined. Thus, our efforts would be still focused on the control measure of $B$. dorsalis, in particular the associations between these control measures and its biology and ecology.

Acknowledgements: We thank our undergraduate students Liang Chang (2008), Shuai Liu, Na Yu (2009), Zhenglong Liu, Bin Xu, Yaowu Peng (2010), Hongmei Cao, Ting Ding (2011), Lele Cheng (2012), Hua Lin (2013), Xinyue Wang and Cong Zhou (2014) who participated in the rearing and trapping tasks between 2008 and 2014. We also thank Dr. Yi Zou from Wageningen University for his help with revising and correcting the manuscript. This work was supported by National Natural Science Foundation of China (No. 31560516), Natural Science Fund of Jiangxi Province (No. 20152ACB21009), and Jiangxi Province Science and Technology Support Program (No. 05143022).

\section{REFERENCES}

1. Al-Mouei R, Choumane W (2014) Assessment of genetic variability within the genus citrus in Syria using SSR markers. American J Exp Agri 4, 939-950.
2. Luo B, Hu JF (2005) Characteristic and preventive measures of the freezing injury of mandarin orange in Jiangxi province. Jiangxi Meteorol Sci Tech 28, 25-27. [in Chinese]

3. Zhou GL, Chen C, Ye J, Hu BS, Liu FQ (2007) Predicting potential ecological distribution of Bactrocera dorsalis in China using GARP ecological niche modeling. Acta Ecol Sin 27, 2262-2269. [in Chinese]

4. Drew RAI, Raghu S (2002) The fruit fly fauna (Diptera: Tephritidae: Dacinae) of the rainforest habitat of the Western Ghats, India. Raffles B Zool 50, 327-352.

5. Aketarawong N, Bonizzoni M, Thanaphum S, Gomulski LM, Gasperi G, Malacrida AR, Gugliemino CR (2007) Inferences on the population structure and colonization process of the invasive oriental fruit fly, Bactrocera dorsalis (Hendel). Mol Ecol 16, 3522-3532.

6. Duyck PF, David P, Quilici S (2004) A review of relationships between interspecific competition and invasions in fruit flies (Diptera: Tephritidae). Ecol Entomol 29, 511-520.

7. Piñero JC, Souder SK, Vargas RI (2013) Residual attractiveness of a spinosad-containing protein-based bait aged under variable conditions to Bactrocera dorsalis and B. cucubitae (Diptera: Tephritidae) wild females in Hawaii. Fla Entomol 96, 1077-1083.

8. Vargas RI, Leblanc L, Putoa R, Eitam A (2007) Impact of introduction of Bactrocera dorsalis (Diptera: Tephritidae) and classical biological control releases of Fopius arisanus (Hymenoptera: Braconidae) on economically important fruit flies in French Polynesia. $J$ Econ Entomol 100, 670-679.

9. Tan KH, Serit M (1994) Adult population dynamics of Bactrocera dorsalis (Diptera: Tephritidae) in relation to host phenology and weather in two villages of Penang Island, Malaysia. Environ Entomol 23, 267-275.

10. Hee AKW, Tan KH (2005) Bioactive fractions containing methyl eugenol-derived sex pheromonal components in haemolymph of the male fruit fly Bactrocera dorsalis (Diptera: Tephritidae). B Entomol Res 95, 615-620.

11. Wang YL (2013) Study advance in incidence and trap control of Bactrocera dorsalis (Hendel). J Environ Entomol 35, 253-259. [in Chinese]

12. Clarke AR, Armstrong KF, Carmichael AE (2005) Invasive phytophagous pests arising through a recent tropical evolutionary radiation: the Bactrocera dorsalis complex of fruit flies. Annu Rev Entomol 50, 293-319.

13. Yuan M, Wang B, Song CB, Rong XL, Yin Y (2008) Effect of climate factors and host plants on population dynamics of Bactrocera dorsalis (Hendel) in Suzhou. J Anhui Agri Sci 36, 9619-9621. [in Chinese]

14. Zhou GL, Ye J, Yuan P, Pan SH (2006) The invasive 
mechanism of Bactrocera dorsalis in Shanghai. Plant Quarantine 20, 44-46. [in Chinese]

15. Zheng SN (2013) Population dynamics and density of Bactrocera dorsalis (Hendel) in different habitats. Acta Ecol Sin 33, 7699-7706. [in Chinese]

16. Ganie SA, Khan ZH, Ahangar RA, Bhat HA, Hussain B (2013) Population dynamics, distribution, and species diversity of fruit flies on cucurbits in Kashmir Valley, India. J Insect Sci 13, 65.

17. Satarkar VR, Krishnamurthy SV, Faleiro JR, Verghese A (2009) Spatial distribution of major Bactrocera fruit flies attracted to methyl eugenol in different ecological zones of Goa, India. Int $J$ Trop Insect Sci 29, 195-201.

18. Xiao C, Li ZY, Chen HR (2004) Research advances in behavior and integrated management of Bactrocera dorsalis (Hendel). Acta Agri Jiangxi 16, 34-40. [in Chinese]

19. Purcell MF, Jackson CG, Long JP, Batchelor MA (1994) Influence of guava ripening on parasitism of the oriental fruit-fly, Bactrocera dorsalis (Hendel) (Diptera: Tephritidae), by Diachasmimorpha longicaudata (Ashmead) (Hymenoptera: Braconidae) and other parasitoids. Biol Control 4, 396-403.

20. Piñero JC, Mau RFL, Vargas RI (2010) Comparison of rain-fast bait stations versus foliar bait sprays for control of oriental fruit fly, Bactrocera dorsalis, in papaya orchards in Hawaii. J Insect Sci 10, 157.

21. Yuan SY, Xiao C, Li ZY, Zhu JY (2003) A study on laboratory rearing techniques for Bactrocera dorsalis (Hendal). Acta Agri Univ Jiangxiensis 25, 577-580. [in Chinese]

22. Li XZ, Wang JG, Xiao HJ, Liu W, Bao HH, Liao $Q$ (2013) The community composition and temporal dynamic of canopy arthropods on Citrus in Nanchang, Jiangxi Province. J Environ Entomol 35, 428-434. [in Chinese]

23. Drew RAI, Hancock DL (1994) The Bactrocera dorsalis complex of fruit flies (Diptera: Tephritidae: Dacinae) in Asia. B Entomol Res 2, 1-68.

24. Aketarawong N, Chinvinijkul S, Orankanok W, Guglielmino CR, Franz G, Malacrida AR, Thanaphum S (2011) The utility of microsatellite DNA markers for the evaluation of area-wide integrated pest management using SIT for the fruit fly, Bactrocera dorsalis (Hendel), control programs in Thailand. Genetica 139, 129-140.

25. Wan XW, Liu YH, Zhang B (2012) Invasion history of the oriental fruit fly, Bactrocera dorsalis, in the PacificAsia region: Two main invasion routes. Plos One 7, e36176.

26. Han P, Wang X, Niu CY, Dong YC, Zhu JQ, Nicolas N (2011) Population dynamics, phenology, and overwintering of Bactrocera dorsalis (Diptera: Tephritidae) in Hubei Province, China. J Pest Sci 84, 289-295.

27. Wan XW, Nardi F, Zhang B, Liu YH (2011) The oriental fruit fly, Bactrocera dorsalis, in China: Origin and gradual inland range expansion associated with population growth. Plos One 6, e25238.

28. Chen P, Ye H (2007) Population dynamics of Bactrocera dorsalis (Diptera: Tephritidae) in Liuku, Yunnan with an analysis of the influencing factors. Acta Entomol Sin 50, 38-45. [in Chinese]

29. Lu X, Han SC, Xu JL, Huang H, Wu H, Ou JF, Sun L (2008) Population dynamics of Bactrocera dorsalis (Hendel) in Guangzhou, Guangdong province, with analysis of the climate factors. Acta Ecol Sin 28, 1850-1856. [in Chinese]

30. Zhou WC, Li WF, Zhan KR, Zhao SX, Chen SL, Ning ZZ, Zhang $\mathrm{H}$ (2008) Field population dynamics of oriental fruit fly in Fujian province. Entomol $J$ East China 17, 26-30. [in Chinese]

31. Chen HD, Zhou CQ, Yang PJ, Liang GQ (1995) On the seasonal population dynamics of melon and orientalfruit flies and pumpkin fly in Guangzhou area. Acta Phytophy Sin 22, 348-354. [in Chinese]

32. Ye H, Liu JH (2005) Population dynamics of Bactrocera dorsalis (Diptera: Tephritidae) in Xishuangbanna of southern Yunnan. Chinese J Appl Ecol 16, 1330-1334. [in Chinese]

33. Chen P, Ye H, Liu JH (2006) Population dynamics of Bactrocera dorsalis (Diptera: Tephritidae) along with analysis on the factors influencing the population in Ruili, Yunnan province. Acta Entomol Sin 26, 2801-2808.

34. Lin JT, Liang GW, Lu YY, Zeng L (2014) Effect of hosts and temperature on biological parameters of Bactrocera dorsalis (Hendel) adult. J Environ Entomol 36, 2-11. [in Chinese]

35. Li Y, WuY, Chen H, Wu J, Li Z (2012) Population structure and colonization of Bactrocera dorsalis (Diptera: Tephritidae) in China, inferred from mtDNA COI sequences. J Appl Entomol 136, 241-251.

36. De Villiers $M$, Hattingh V, Kriticos DJ, Brunel S, Vayssières JF, Sinzogan A, Billah MK, Mohamed SA, et al (2016) The potential distribution of Bactrocera dorsalis: Considering phenology and irrigation patterns. B Entomol Res 106, 19-33. 